\title{
Managing Resources and Need for Cognition: Impact on Depressed Mood at Work
}

Vickie Coleman Gallagher

Cleveland State University, v.c.gallagher@csuohio.edu

Follow this and additional works at: https://engagedscholarship.csuohio.edu/bus_facpub

Part of the Organizational Behavior and Theory Commons

How does access to this work benefit you? Let us know!

\section{Publisher's Statement}

NOTICE: this is the author's version of a work that was accepted for publication in Personality and Individual Differences. Changes resulting from the publishing process, such as peer review, editing, corrections, structural formatting, and other quality control mechanisms may not be reflected in this document. Changes may have been made to this work since it was submitted for publication. A definitive version was subsequently published in Personality and Individual Differences, 53 (2012); 10.1016/j.paid.2012.04.025

\section{Original Published Citation}

Gallagher, V. C. (2012). Managing Resources and Need for Cognition: Impact on Depressed Mood at Work. Personality and Individual Differences, 53, pp. 534-537.

This Article is brought to you for free and open access by the Monte Ahuja College of Business at EngagedScholarship@CSU. It has been accepted for inclusion in Business Faculty Publications by an authorized administrator of EngagedScholarship@CSU. For more information, please contact library.es@csuohio.edu. 


\title{
Managing resources and need for cognition: Impact on depressed mood at work
}

\author{
Vickie Coleman Gallagher* \\ Cleveland State University, Management and Labor Relations, Monte Ahuja College of Business Administration, 1860 East, 18th St., Rm. 443, Cleveland, OH 44115, United States
}

\section{Introduction}

Stress is the most common reason US workers quit (Leading productivity killers in today's market: Overwork, stress, 2008). with stress often leading to mental health problems accounting for $47 \%$ of long-term workplace absences (O'Reilly, 2008). Individuals differ in ability to manage inevitable workplace stressors. This research identifies individual differences in coping and discusses ways to aid coping. Conservation of resources (COR) theory integrates several stress theories (Hobfoll, 1989) and provides a framework for understanding stress through resource management. Psychological stress is a reaction to threats, actual loss, or a lack of gain following investment of resources (Hobfoll, 1989). Once stressors are identified, individuals strive to restore equilibrium (Aspinwall \& Taylor, 1997) and aim to retain, protect, and build resources (Hobfoll, 1989). Multiple resources are preferred since "single resources, even if strong, may be insufficient to cope with real-life stressors" (Hobfoll \& Shirom, 2000).

Belongings, for example, are valued because of their physical nature and the status they symbolize (Hobfoll, 1989). Other resources include characteristics (e.g., self-esteem), conditions (e.g., tenure), and energies to aid the attainment of other resources (Hobfoll, 1989). Hence, individuals are not equally capable of acquiring resources. Of particular interest is one's ability to conserve and manage resources at work, as well as differences in need for cognition (NFC). NFC is a stable individual difference (Cacioppo $\&$ Petty, 1982) in one's tendency to enjoy effortful cognitive activity. The current research will investigate how NFC and ability to manage resources interact to mitigate depressed mood at work (DMW).

\footnotetext{
* Tel.: +1 216687 4711: fax: +1216 6874708 .

E-mail addresses: vcgallagher@att.net, v.c.gallagher@csuohio.edu
}

\subsection{Ability to manage resources}

Research has shown that individuals differ in their ability to manage resources (Hochwarter, Perrewé, Meurs, \& Kacmar, 2007). Hobfoll (2001) explains that resource utilization may include optimization strategies (Baltes \& Baltes, 1990; Baltes, 1997), compensation strategies, or proactive coping. If a worker suffers an injury (e.g., resource loss), they may optimize other resources by rearranging workstations, using a cane, or seeking assistance. Hochwarter's measure, developed based on COR theory. focuses on ability to manage one's workplace through variations in exertion, respite, utilization of equipment/personnel, and assistance (Hochwarter, Laird, \& Brouer, 2008). Hobfoll (2001) conceptualized work resources as having the tools whereas Hochwarter et al. (2007) operationalized it as ability to manage or mobilize resources.

This ability is associated with increased satisfaction and well being (Hochwarter et al., 2007; Thompson \& Prottas, 2005) shown to mitigate the traumatic effects of hurricane induced stress (Hochwarter et al., 2008). This ability minimized the effects of work-induced guilt (Hochwarter et al., 2007) and buffered against the stressor of accountability (Zellars, Hochwarter, Lanovich, Perrewé, \& Ferris, 2011). However, the current research is also concerned with a second individual difference variable - NFC.

\subsection{Need for cognition}

Individuals differ in terms of cognitive motivation to engage in and enjoy information processing (Cacioppo \& Petty, 1982) - repeated or prolonged problem solving (Cacioppo, Petty, Kao, \& Rodriguez, 1986). Persons high in NFC make sense of relationships and events by acquiring information and reflecting. They differ in 
the acquisition and processing of information (Cacioppo, Petty, Feinstein, \& Jarvis, 1996) and enjoy learning new ways of thinking about problems; persons low in NFC are cognitive misers (Cacioppo et al., 1986). NFC correlates with academic performance $\left(r_{\text {ave }}=0.26\right)$, argued to covary because cognitive motivation is related to (not redundant with) intellectual ability (Cacioppo et al., 1996). NFC has received significant attention in the social sciences as evident by a literature review of over 100 studies (Cacioppo et al., 1996), with research conducted primarily among undergraduates, in experimental designs, and with community residents about policy issues.

A few workplace studies illustrate that persons high in NFC are more likely to report higher performance (Deeter-Schmelz \& Sojka, 2007) as well as higher average sales (Sojka \& Deeter-Schmelz, 2008), pointing to the benefits of NFC, even in roles that rely on relationships. Kearney, Gerbert, and Voelpel (2009) found that NFC moderated the relationship between team diversity and performance such that NFC enhanced the team's ability to elaborate on task-relevant information (minimizing tendencies to rely on more simple cues, heuristics, or stereotypes by processing a broader range of information). Persons low in NFC likely found team endeavors frustrating (Kearney et al., 2009).

NFC is defined as a cognitive motivation and behavioral tendency rather than pure intellectual capacity (Cacioppo \& Petty, 1982). Interestingly, Hobfoll (2002) believes information processing to be costly, and that arousal can tax cognitive resources (Keinan, Friedland, Kahneman, \& Roth, 1999). Furthermore, "those who possess resources are more capable of solving the problems inherent in stressful circumstances... circumstances can be seen as a life puzzle that must be unraveled. If they have more resources, people are more likely to have either the specific resources needed to fit demands or resources that can provide them access to the (appropriate) resources" (Hobfoll, 2002; 318). As such, NFC may also be considered a resource.

I argue that when individuals have ability to manage resources and enjoy analyzing situations, information processing is less taxing. Individuals with high NFC are more likely to enjoy and engage in effortful problem-solving activities without feeling drained; hence, when combined with the confidence to manage one's workplace resources, this should lead to enhanced outcomes in the form of lower DMW.

DMW is a general feeling of despair, correlated with irritability, low energy, decreased work interest, and decreased sense of usefulness (Quinn \& Sheppard, 1974). Antecedents to DMW include role strain (Beehr, 1976), role overload (Beehr, 1981), interpersonal conflict (Heinisch \& Jex, 1997), and lack of job control (Erickson \& Wharton, 1997). Examining DMW is particularly important for organizational researchers given the long-term consequences: lower performance, fewer citizenship behaviors, burnout, and turnover (Stoner \& Perrewé, 2006). Hobfoll (2002) argued that psychological resources give individuals a sense of resiliency over their environment. I argue that ability to manage resources and high NFC will lower levels of DMW.

Hypothesis 1: NFC moderates the relationship between ability to manage resources and DMW relationship, such that the negative relationship between ability to manage resources and DMW will be stronger when NFC is higher.

\section{Method}

\subsection{Sample}

Antecedents were collected at Time 1, outcomes at Time 2, approximately 1 month later, to minimize priming. (Priming is a risk since "ability to manage resources" contains language about stressful workplaces.) http://www.Qualtrics.com software was used employing forced-choice responses. Hence, 382 potential respondents began the survey, 286 completed Time 1 , and 213 adults responded to all survey items in Time 2 (for a response rate of $56 \%$ ). Most (90\%) were working full-time; $43 \% \mathrm{men}$; average age 40 years $(S D=13.4)$. Race was primarily white $(78 \%)$, with some Hispanics (8\%) and African Americans (7\%). Most had at least some college $(37 \%)$ or graduated with undergraduate degrees $(34 \%)$. Organizational tenure was 7.5 years $(S D=8.9)$. Of the 73 who completed $\mathrm{T} 1$ not $\mathrm{T} 2$, respondents were younger (average age $=34$ years; $S D=13.5$ ). SAS sample selection bias analysis revealed that attrition was not missing at random (NMAR). However, the interaction term was still significant and in the hypothesized direction, as reported below.

I recruited respondents with assistance of undergraduates attending university in the Southeastern US. Students emailed links to family/friends working full-time. This snowball data collection (Treadway et al., 2005) attempts to increase generalizability across multiple contexts (Hochwarter et al., 2007).

\subsection{Measures - Antecedents (Time 1)}

\subsubsection{Ability to manage resources}

Ability to manage resources is a 6-item measure (Hochwarter et al., 2007), 1 to 5 scale, with 1 representing "strongly disagree" and 5 "strongly agree". Sample items are, "When work is stressful, I am able to conserve my energy" and "I can change my behavior at work to make sure I don't run on an empty tank” $(\alpha=.76)$.

\subsubsection{Need for cognition (NFC)}

NFC is an 18-item measure (Cacioppo, Petty, \& Kao, 1984) (same 1 to 5 scale). Items include, "I would prefer complex to simple problems" and "I really enjoy a task that involves coming up with new solutions to problems" $(\alpha=.83)$.

\subsection{Measures - Outcomes (Time 2)}

\subsubsection{Depressed mood at work (DMW)}

DMW is a 10 -item measure (Quinn \& Sheppard, 1974), 1 to 4 scale, with 1 representing "never" and 4 "often" feel this way when thinking about work. Items include "I feel downhearted and blue at work" and "I find myself restless and can't keep still at work" $(\alpha=.87)$.

\subsubsection{Age (control variable)}

Age is likely to influence one's ability to acquire resources, as well as likelihood of having had time to acquire resources

\subsection{Analysis}

A four step moderated hierarchical regression was conducted (Cohen \& Cohen, 1983). First, age was entered into the equation. Second, the centered main effect of ability to manage resources was entered. Next, the centered main effect of NFC and then the centered interaction term (ability to manage resources $\times$ NFC) was entered.

\section{Results}

Means, standard deviations, and bi-variate correlations are in Table 1. Ability to manage resources was negatively related to DMW $(r=-.28, p<.01)$. NFC was negatively related to DMW $(r=-.15, p<.05)$, consistent with prior research correlating NFC with stress outcomes (Cacioppo et al., 1996). Age was negatively related to DMW $(r=-.22, p<.01)$. 
Table 1

Descriptive statistics: means, standard deviations, and correlations.

\begin{tabular}{|c|c|c|c|c|c|c|}
\hline Variable & M & SD & 1 & 2 & 3 & 4 \\
\hline 1. Age & 39.63 & 13.45 & & & & \\
\hline 2. Ability to manage resources & 3.21 & .73 & -.10 & - & & \\
\hline 3. NFC & 3.64 & .52 & $.14^{*}$ & .11 & - & \\
\hline 4. DMW & 1.73 & .50 & $-.22^{* *}$ & $-.28^{* *}$ & $-.15^{*}$ & - \\
\hline
\end{tabular}

Table 2 reports results from the regression predicting DMW. Controlling for age, ability to manage resources is significantly (negatively) related to DMW ( $\beta=-.30, p<.01)$, explaining $9 \%$ of the variance $(p<.01)$. The interaction of ability to manage resources $\times$ NFC $(\beta=-.13, p<.05)$ was significantly (negatively) related to DMW, providing $2 \%(p<.05)$ incremental variance.

Per Fig. 1, as ability to manage resources increases, DMW goes down for those with high NFC $(\beta=.28 ; p<.01)$ and average NFC $(\beta=.19 ; p<.01)$, but not low NFC $(\beta=.11 ; p=.098)$ based on the simple slopes analysis. Hypothesis 1 was supported.

\section{Discussion}

This research supports my hypothesis that NFC and ability to manage resources interact to minimize DMW. The negative relationship was stronger when NFC was higher. This research contributes to a growing body of resource management literature. Ability to manage resources at work (pacing oneself, requesting help, and conserving energy) positively impacts job and life satisfaction (Hochwarter et al., 2007) and minimizes job tension (Hochwarter et al., 2008).

Hochwarter et al. (2007) argue that these individuals regulate behavior, adapting to unpredictable demands (Murven \& Baumeister, 2000). "Even when situational factors evoke comparable effortful cognitive processing across individuals, individual differences may still manifest in their enjoyment (or disaffection) in thinking" (Cacioppo et al., 1996, p. 197). While problem solving to cope is a component of NFC, cognition is viewed as an enjoyable activity (Cacioppo et al., 1996), perhaps being less likely to drain resources during information processing.

This research informs COR theory and answers the call (Hobfoll \& Shirom, 2000) for the investigation into complex interactions between individual differences variables that can affect outcomes. Resources act in unison and are more helpful than single resources. This study does of course have limitations. Only self-reported perceptual data were collected and attrition from T1 to T2 limits generalizability. Although a pattern of elevated correlations is not

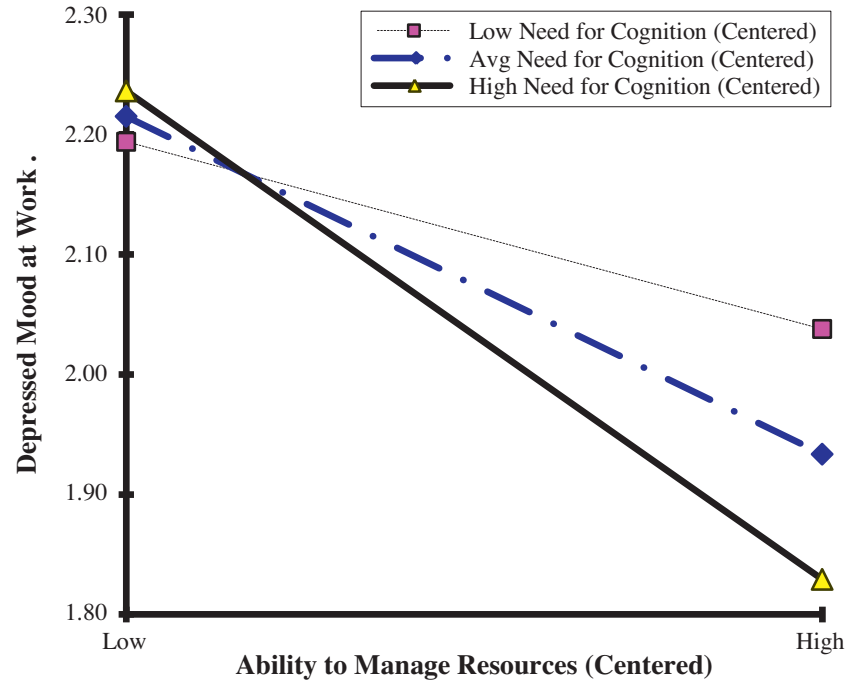

Fig. 1. The interactive effects of ability to manage resources and NFC on DMW. Note: Unstandardized; Low = $-1 \mathrm{SD} ; \mathrm{Avg}=$ at Mean; High = +1 SD.

apparent via the correlation matrix, future research should consider other-reports and objective data sources. Furthermore, future research should include explicit measures of stressors within the model. Although ability to manage resources implies a stressor (e.g., I pace myself "when things get hectic"), the study does not include specific stressors.

COR theory lacks specificity in enumerating resources, as it lays out broad categories such as objects, conditions, characteristics, and energies. It is conceivable that almost any construct in the context of the work and non-work environment could be a resource. The critical research needed to test COR must overcome the challenge of defining resources a priori such that theoretical propositions can be falsified. To test losses or gains adequately, longitudinal designs are needed. Future research should consider individual differences (within-person), as well as differences between persons (as collected in the current research).

Examining individual differences as resources will be critical for COR theory to advance, such as personality, needs, etc. Resources likely affect each other such that gaining one leads to acquiring others - "resource spirals" per COR theory. Hobfoll (2001) refers to these as caravans, such that resources aggregate over time. The present study is a minor step in examining the effects of two individual differences as possible "resources" to mitigate felt strain within the workplace. Finally, future research should explore the spillover benefits of NFC/resource management into non-work domains (such as one's ability to minimize work-family conflict).

Table 2

Ability to manage resources and NFC predicting DMW.

\begin{tabular}{|c|c|c|c|c|c|c|c|c|}
\hline \multirow[t]{2}{*}{ Step/Variable } & \multicolumn{2}{|l|}{ Step 1} & \multicolumn{2}{|l|}{ Step 2} & \multicolumn{2}{|l|}{ Step 3} & \multicolumn{2}{|l|}{ Step 4} \\
\hline & $\beta$ & $R 2$ & $\beta$ & $\Delta R 2$ & $\beta$ & $\Delta R 2$ & $\beta$ & $\Delta R 2$ \\
\hline $\begin{array}{l}\text { Step } 1 \\
\text { Age }\end{array}$ & $-.22^{* *}$ & .05 & $-.25^{* *}$ & & $-.24^{* *}$ & & $-.22^{* *}$ & \\
\hline $\begin{array}{l}\text { Step } 2 \\
\text { Ability to manage resources (A) }\end{array}$ & & & $-.30^{* *}$ & .09 & $-.29^{* *}$ & & $-.28^{* *}$ & \\
\hline $\begin{array}{l}\text { Step } 3 \\
\text { NFC (B) }\end{array}$ & & & & & -.08 & .00 & -.08 & \\
\hline $\begin{array}{l}\text { Step } 4 \\
\mathrm{~A} \times \mathrm{B}\end{array}$ & & & & & & & $-.13^{*}$ & .02 \\
\hline
\end{tabular}

$N=213$.

${ }^{*} p<.05$.

$p<.01$. 


\section{References}

Aspinwall, L. G., \& Taylor, S. E. (1997). A stitch in time: Self-regulation and proactive coping. Psychological Bulletin, 121(3), 417-436.

Baltes, M. M., \& Baltes, P. B. (1990). Psychological perspectives on successful aging: The model of selective optimization with compensation. In P. B. Baltes \& M. M Baltes (Eds.), Successful aging: Perspectives from the behavioral sciences (pp. 1-34). New York: Cambridge University Press.

Baltes, R. B. (1997). On the incomplete architecture of human ontogeny: Selection, optimization, and compensation as foundation of development theory. American Psychologist, 52, 366-380.

Beehr, T. A. (1976). Perceived situational moderators of the relationship between subjective role ambiguity and role strain. Journal of Applied Psychology, 61(1), 35-40.

Beehr, T. A. (1981). Work-role stress and attitudes towards co-workers. Group and Organization Studies, 6, 201-210.

Cacioppo, J. T., \& Petty, R. E. (1982). The need for cognition. Journal of Personality and Social Psychology, 42(1), 116-131.

Cacioppo, J. T., Petty, R. E., Feinstein, J. A., \& Jarvis, W. B. G. (1996). Dispositional differences in cognitive motivation: The life and times of individuals varying in need for cognition. Psychological Bulletin, 119(2), 197-253.

Cacioppo, J. T., Petty, R. E., \& Kao, C. F. (1984). The efficient assessment of need for cognition. Journal of Personality Assessment, 48, 306-307.

Cacioppo, J. T., Petty, R. E., Kao, C. F., \& Rodriguez, R. (1986). Central and peripheral routes to persuasion: An individual difference perspective. Journal of Personality and Social Psychology, 51, 1032-1043.

Cohen, J., \& Cohen, P. (1983). Applied multiple regression/correlation analysis for the behavioral sciences (2nd ed.). Hillsdale, NJ: Erlbaum.

Deeter-Schmelz, D. R., \& Sojka, J. Z. (2007). Personality traits and sales performance: Exploring differential effects of need for cognition and self-monitoring. Journal of Marketing Theory \& Practice, 15(2), 145-157.

Erickson, R. J., \& Wharton, A. S. (1997). Inauthenticity and depression: Assessing the consequences of interactive service work. Work and Occupations, 24, 188-213.

Heinisch, D. A., \& Jex, S. M. (1997). Negative affectivity and gender as moderators of the relationship between work-related stressors and depressed mood at work Work \& Stress, 11, 46-57.

Hobfoll, S. E. (1989). Conservation of resources: A new attempt at conceptualizing stress. American Psychologist, 44(3), 513-524.

Hobfoll, S. E. (2001). The influence of culture, community, and the nested-self in the stress process: Advancing conservation of resources theory. Applied Psychology: An International Review, 50, 337-421.

Hobfoll, S. E. (2002). Social and psychological resources and adaptation. Review of General Psychology, 6, 307-324.
Hobfoll, S. E., \& Shirom, A. (2000). Conservation of resources theory: Application to stress and management in the workplace. In R. T. Golembiewski (Ed.), Handbook of organization behavior (pp. 57-81). New York: Dekker.

Hochwarter, W. A., Laird, M. D., \& Brouer, R. L. (2008). Board up the windows: The interactive effects of hurricane-induced job stress and perceived resources on work outcomes. Journal of Management, 34(2), 263-289.

Hochwarter, W. A., Perrewé, P. L., Meurs, J. A., \& Kacmar, C. (2007). The interactive effects of work-induced guilt and ability to manage resources on job and life satisfaction. Journal of Occupational Health Psychology, 12(2), 125-135.

Kearney, E., Gerbert, D., \& Voelpel, S. C. (2009). When and how diversity benefits teams: The importance of team members' need for cognition. Academy of Management Journal, 53(3), 581-598.

Keinan, G., Friedland, N., Kahneman, D., \& Roth, D. (1999). The effect of stress on the suppression of erroneous competing responses. Anxiety, Stress, and Coping, 12, 455-476.

Leading productivity killers in today's market: Overwork, stress. (2008, April). HR Focus, 85, 8

Murven, M., \& Baumeister, R. (2000). Self-regulation and depletion of limited resources: Does self-control resemble a muscle? Psychological Bulletin, 126, 247-259.

O'Reilly, S. (2008). Making work better. Occupational Health, 60(6), 22.

Quinn, R. P., \& Sheppard, L. (1974). The 1972-1973 quality of employment survey. Ann Arbor, MI: University of Michigan, Institute for Social Research.

Sojka, J. Z., \& Deeter-Schmelz, D. R. (2008). Need for cognition and affective orientation as predictors of sales performance. An investigation of main and interaction effects. Journal of Business Psychology, 22, 179-190.

Stoner, J., \& Perrewé, P. L. (2006). Consequences of depressed mood at work: The importance of supportive superiors. In A. M. Rossi, P. L. Perrewé, \& S. L. Sauter (Eds.), Stress \& quality of working life: Current perspectives in occupational health (pp. 87-99). Greenwich, CT: Information Age Publishing, Inc.

Thompson, C. A., \& Prottas, D. J. (2005). Relationships among organizational family support, job autonomy, perceived control, and employee well-being. Journal of Occupational Health Psychology, 10, 100-118.

Treadway, D. C., Ferris, G. R., Hochwarter, W., Perrewé, P., Witt, L. A., \& Goodman, J. M. (2005). The role of age in the perceptions of politics-job performance relationship: A three-study constructive replication. Journal of Applied Psychology, 90, 872-881.

Zellars, K., Hochwarter, W., Lanovich, S. E., Perrewé, P. L., \& Ferris, G. R. (2011). Accountability for others, perceived resources, and well being: Convergent restricted non-linear results in two samples. Journal of Occupational and Organizational Psychology. http://dx.doi.org/10.1348/2044-8325.002004 [Early online view]. 